\title{
Expression of molecules of the Wnt pathway and of E-cadherin in the etiopathogenesis of human thymomas
}

\author{
PROKOP VODICKA $^{1,2}$, LENKA KRSKOVA ${ }^{1}$, IGOR ODINTSOV $^{1}$, \\ LUDMILA KRIZOVA $^{3}$, EVA SEDLACKOVA ${ }^{3}$, JAN SCHUTZNER ${ }^{4}$ and JOSEF ZAMECNIK ${ }^{1}$
}

\begin{abstract}
${ }^{1}$ Department of Pathology and Molecular Medicine, Second Faculty of Medicine, Charles University and Motol University Hospital, Prague $15006 ;{ }^{2}$ First Department of Medicine and ${ }^{3}$ Department of Oncology, First Faculty of Medicine, Charles University and General University Hospital, Prague 128 08; ${ }^{4}$ Third Department of Surgery, First Faculty of Medicine, Charles University and Motol University Hospital, Prague 150 06, Czech Republic
\end{abstract}

Received August 4, 2019; Accepted December 10, 2019

DOI: $10.3892 / 01.2020 .11343$

\begin{abstract}
The molecular pathogenesis of thymoma remains largely unknown. It has been recently demonstrated, that activation of Wnt signaling pathway leads to increased incidence of thymoma in murine models. The present study investigated the activation of molecules of the Wnt signaling pathway in human thymoma. A total of 112 thymoma cases with complete clinical and follow-up data and 8 controls were included in the present study. Patients with thymoma and controls were examined immunohistochemically for $\beta$-catenin and E-cadherin. The mRNA expression levels of CTNNB1,CCND1, MYC, AXIN2 and CDH1 were analyzed by reverse transcription-quantitative PCR. Immunohistochemically, $\beta$-catenin and E-cadherin were overexpressed in neoplastic cells of all thymomas. In type A, $\mathrm{B} 1$ and non-invasive type $\mathrm{B} 2$ thymoma, both molecules were located in the cytoplasm, in contrast to invasive type B2 and B3 thymoma, where membranous immunopositivities were observed. mRNA expression levels of genes involved in the Wnt pathway and of E-cadherin were significantly increased in both type A and B thymoma compared with controls; increasing gradually from type B1 to B3, and with higher stage of disease. In recurrent type B thymoma, the mRNA expression of the molecules was significantly higher. Despite the activation of Wnt pathway in indolent type A thymoma, the negative feedback of the pathway was preserved by overexpression of inhibitory molecule
\end{abstract}

Correspondence to: Professor Josef Zamecnik, Department of Pathology and Molecular Medicine, Second Faculty of Medicine, Charles University and Motol University Hospital, V Uvalu 84, Prague 150 06, Czech Republic

E-mail: josef.zamecnik@fnmotol.cz

Abbreviations: TEC, thymic epithelial cells; MG, myasthenia gravis; F, female; M, male; AID, autoimmune disorder

Key words: thymoma, Wnt, $\beta$-catenin, E-cadherin, axin2 axin2, which was not overexpressed in type B thymoma. In summary, the Wnt pathway was activated in human thymoma and may contribute to oncogenesis. Detection of molecules of the Wnt pathway may be of diagnostic and prognostic value.

\section{Introduction}

Thymomas are rare malignant tumors arising from thymic epithelial cells (TEC). According to the current WHO classification based on morphology of the tumors, thymomas are divided into two groups (1). Type A thymomas represent indolent tumors with slow growth and favorable clinical course, comprised of spindle or oval epithelial cells with a little or no admixture of non-neoplastic mature T lymphocytes. Type B thymomas are subdivided into three entities with different proportion of non-neoplastic immature T lymphocytes to neoplastic TEC-type B1 (abundance of T cells), type B2, and type B3 (rich in epithelial cells). Type B thymomas possess higher malignant potential rising from type B1 up to type B3. In some cases, more than one neoplastic component is present leading to a mixed designation as thymoma type $\mathrm{AB}$ comprising both type $\mathrm{A}$ and type $\mathrm{B}$ components or thymoma comprising two subtypes of type B.

The molecular pathogenesis of these rare tumors remains widely unknown and only a couple of molecular events have been related to tumor biology of thymomas so far (2-4). Recently, Liang et al (5) showed that induced overexpression of $\beta$-catenin in TEC of murine models leads to higher incidence of thymomas exhibiting histological and molecular characteristics of human B3 thymomas. Additionally, this study identified upregulation of multiple Wnt/ $\beta$-catenin-targeted genes corroborating causality of this pathway in the tumor development.

Since there is no data investigating the involvement of Wnt signaling pathway in pathogenesis of human thymomas, we analyzed the expression of molecules $\beta$-catenin, cyclin D1, c-myc, and axin2, and of molecule E-cadherin in thymomas, and studied the potential role of their detection for thymoma diagnosis and its clinical relevance. 


\section{Materials and methods}

Patient characteristics. A total of 112 thymoma cases (58 female and 54 male patients) and 8 control subjects entered into our study.

The thymoma group consisted of 15 patients with thymoma type A and 97 patients with thymoma type B undergoing surgical resection of anterior mediastinal tumor at the Third Department of Surgery, Motol University Hospital (Prague, Czech Republic) between January 2008 and July 2017. Mean age was 54.3 years (range 22-86 years). Medical records of each patient were reviewed in detail and the following features were recorded: Gender, age at the time of surgery, size of tumor, presence of myasthenia gravis (MG) or other autoimmune disorders, as well as synchronous malignant neoplasms at the time of first presentation. Since the age over 60 has been previously shown as a significant prognostic factor in malignancies of hematopoietic system (6,7), we also divided our group of patients according to their age to evaluate potential age-specific features of the disease. All patients were treated according to current guidelines for treatment of thymomas (8) at the Department of Oncology, General University Hospital (Prague, Czech Republic), and follow-up data were retrieved from their files. Detailed clinical characteristics of patients enrolled into the study are given in Table I.

Since the thymus undergoes physiologically involution during late childhood (9), the control thymic tissue for our study was obtained from pediatric patients during cardiac surgery at the Children's Heart Centre, Motol University Hospital; the control group of non-neoplastic thymic tissue was retrieved from 2 female patients and 6 male patients. Mean age was 1.5 years (range 1-3 years).

Written informed consent from each patient/guardian was obtained prior to the enrollment, and the study was approved by the Ethics committee of the Second Faculty of Medicine, Charles University.

Histopathology and staging. All surgical pathology analyzes were performed at the Department of Pathology and Molecular Medicine, Motol University Hospital (Prague, Czech Republic). Resected tissues were routinely fixed in $10 \%$ formalin and embedded in paraffin. Each thymic tumor as well as the control thymic tissue were examined in several tissue blocks; the most appropriate tissue block (e.g. with the invasive component of the tumors) was used for further studies in each case. From the tissue blocks, $4 \mu \mathrm{m}$ sections were examined microscopically (microscope BX51; Olympus) by routine hematoxylin-eosin staining to ensure the quality and the relevance of the harvested tissue. Further serial tissue sections were used for immunohistochemistry and for the RNA isolation.

The resected specimens were reviewed to establish the type of thymoma according to the actual WHO classification of thymic tumors including the invasivity of tumors according to the modified Masaoka-Koga clinical staging of thymomas (10). In 12 cases (11\%), the tumor contained both type B2 and B3 component; the sample entered the group according to the predominant component in the tissue block. No thymic carcinomas as well as micronodular thymomas or type $\mathrm{AB}$ thymomas were enrolled into the study.
Immunohistochemistry. Each case of thymoma was evaluated immunohistochemically. For immunohistochemical purposes, $4 \mu \mathrm{m}$ thick serial sections were recut from the tissue block. Tissue sections were deparaffinized and rehydrated. Heat-induced epitope retrieval was performed in sodium citrate buffer solution ( $\mathrm{pH}$ 6.0) warming up to $96^{\circ} \mathrm{C}$ in water bath for $40 \mathrm{~min}$. Following cooling for $20 \mathrm{~min}$ and blocking of endogenous peroxidase activity, sections were incubated overnight at $4^{\circ} \mathrm{C}$ with mouse monoclonal antibody against $\beta$-catenin (clone 14/ $\beta$-catenin, BD Biosciences), diluted 1:1,500, and E-cadherin (NCL-L-E-Cad; Novocastra Laboratories Ltd.), diluted 1:60. The antigen-antibody complexes were visualized by biotin-streptavidin detection systems (N-Histofine Simple Stain MAX PO; Nichirei Corporation); chromogenic development was performed using 3,3-diaminobenzidine. All sections were counterstained slightly with Harris' hematoxylin. Positive and negative controls were used in each assay.

The results of immunohistochemical assays for both molecules were evaluated in tumors and in controls considering their localization (membranous, cytoplasmic or nuclear), as well as intensity. The expression of the molecules was noted both in the center of the tumor mass and in its periphery, especially in case of invasive tumors.

\section{Quantitative mRNA expression analysis}

$R N A$ extraction and preparation of complementary DNA (cDNA) by reverse transcription. Total RNA was isolated from paraffin sections of the samples using extraction with High Pure RNA Paraffin kit (Roche Diagnostic) according to the manufacturer's instructions. The complementary DNA (cDNA) was synthesized using MMLV Reverse Transcriptase (Invitrogen) from $10 \mu \mathrm{l}$ total mRNA in a volume of $20 \mu \mathrm{l}$. The reaction mixture contained Tris- $\mathrm{HCl} 50 \mathrm{mM}, \mathrm{pH} 8.3 ; \mathrm{KCl}$ $75 \mathrm{mM} ; \mathrm{MgCl}_{2} 3 \mathrm{mM}$; dithiothreitol $10 \mathrm{mM}$; dNTP $0.5 \mathrm{mM}$ each; random hexamers $12.5 \mathrm{mM}$ and 50 units of MMLV Reverse Transcriptase according to the manufacturer's instructions. Reverse transcription included an incubation period of $60 \mathrm{~min}$ at $37^{\circ} \mathrm{C}$.

Reverse transcription-quantitative $P C R$ (RT-qPCR). RT-qPCR analyses were performed using LightCycler ${ }^{\circledR} 480$ Instrument II (Roche Diagnostics). RT-qPCR for housekeeping gene $B 2 M$ ( $\beta 2$-microglobulin) using the hydrolyzation probe was utilized to evaluate the amount and amplifiability of cDNA. The primers for $B 2 M$ were designed as reported by Bijwaard et al (11) and are given in Table II. Relative mRNA expressions of CTNNB1 ( $\beta$-catenin), CCND1 (cyclin D1), $M Y C$ (c-myc), AXIN2 (axin2), and CDH1 (E-cadherin) were evaluated by RT-qPCR using TaqMan Master Mix II and primers and probes of TaqMan Assays (Applied Biosystems), as outlined by the manufacturer's instructions. TaqMan Assays used in this study are given in Table III. All analyses were performed in duplicates and the mean values were taken for further calculations.

Evaluation of $R T-q P C R$ results. The mRNA expressions of $C T N N B 1, C C N D 1, M Y C, A X I N 2$, and $C D H 1$ were calculated using the relative quantification, i.e. the $\Delta \Delta \mathrm{Cq}$ methods, based on the expression levels of a target gene versus the reference housekeeping gene $B 2 M$ (12). In brief, fluorescence was 
Table I. Detailed clinical characteristics of patients with thymoma enrolled in the present study.

\begin{tabular}{|c|c|c|c|c|c|c|c|c|c|c|c|}
\hline \multirow{2}{*}{$\begin{array}{l}\text { WHO } \\
\text { type }\end{array}$} & \multirow[b]{2}{*}{ Patients, $\mathrm{n}$} & \multirow[b]{2}{*}{$\mathrm{F} / \mathrm{M}, \mathrm{n}$} & \multirow{2}{*}{$\begin{array}{l}\text { Age, } \\
\text { years }\end{array}$} & \multicolumn{4}{|c|}{$\begin{array}{c}\text { Masaoka-Koga } \\
\text { stage }\end{array}$} & \multirow{2}{*}{$\begin{array}{l}\mathrm{MG} \\
\mathrm{n}(\%)\end{array}$} & \multirow{2}{*}{$\begin{array}{c}\text { Other } \\
\text { AID, n }(\%)\end{array}$} & \multirow{2}{*}{$\begin{array}{l}\text { Recurrence, } \\
\text { n (\%) }\end{array}$} & \multirow{2}{*}{$\begin{array}{c}\text { Synchronous } \\
\text { malignancy, n (\%) }\end{array}$} \\
\hline & & & & I & II & III & IV & & & & \\
\hline Type A & 15 & $5 / 10$ & $55.3 \pm 13.1$ & 13 & 2 & 0 & 0 & $11(73)$ & 0 & 0 & $3(20)$ \\
\hline Type B1 & 19 & $9 / 10$ & $52.2 \pm 15.0$ & 11 & 4 & 4 & 0 & $13(68)$ & $1(5)$ & 0 & 0 \\
\hline Type B2 & 41 & $26 / 15$ & $56.9 \pm 14.0$ & 13 & 18 & 2 & 8 & $26(63)$ & $3(7)$ & $5(12)$ & $3(7)$ \\
\hline Type B3 & 37 & $14 / 23$ & $52.1 \pm 14.1$ & 4 & 17 & 11 & 6 & $19(51)$ & $5(14)$ & $4(10)$ & $4(11)$ \\
\hline Total & 112 & $54 / 58$ & $54.3 \pm 14.2$ & 41 & 39 & 16 & 14 & $69(62)$ & $9(8)$ & $9(8)$ & $10(9)$ \\
\hline
\end{tabular}

Age is presented as the mean $\pm \mathrm{SD}$. F, female; M, male; AID, autoimmune disorder; WHO, World Health Organization; MG, myasthenia gravis .

Table II. Primers and probes used in the present study.

\begin{tabular}{ll}
\hline Target & \multicolumn{1}{c}{$\begin{array}{c}\text { Primers and probes }\left(5^{\prime}-3^{\prime}\right) \text { or } \\
\text { TaqMan Assays }\end{array}$} \\
\hline$\beta 2$-microglobulin & $\begin{array}{l}\text { Forward: TGACTTTGTCACAGCCCAA } \\
\text { GATA } \\
\text { Reverse: AATCCAAATGCGGCATCTTC } \\
\text { Probe: TGATGCTGCTTACATGTCTCG } \\
\text { ATCCCA }\end{array}$ \\
\hline
\end{tabular}

Table III. TaqMan Assays used in the present study.

\begin{tabular}{lc}
\hline Molecule (gene) & Assay ID \\
\hline$\beta$-catenin $(C T N N B 1)$ & Hs00355049_m1 \\
C-myc $(M Y C)$ & Hs00153408_m1 \\
Cyclin D1 $(C C N D 1)$ & Hs00765553_m1 \\
Axin2 $(A X I N 2)$ & Hs00610344_m1 \\
E-cadherin $(C D H 1)$ & Hs01023894_m1
\end{tabular}

detected continually after each cycle of PCR reaction. Data were analyzed with the use of the LightCycler ${ }^{\circledR} 480$ Software, version 1.5 (Roche Diagnostics). The software determines a threshold line based on the baseline fluorescent signal, and the cycle where the fluorescent signal crosses the threshold is recorded as the $\mathrm{Cq}$ value, which is inversely proportional to the starting number of template copies. The average $\mathrm{Cq}$ value for $B 2 M$ was subtracted from the average of $\mathrm{Cq}$ value of the gene of interest to yield the $\Delta \mathrm{Cq}$ value, which is inversely proportional to the relative amount of target nucleic acid in the sample. Next, the $\Delta \mathrm{Cq}$ value of the control sample was subtracted from the $\Delta \mathrm{Cq}$ value of the studied sample to yield the $\Delta \Delta \mathrm{Cq}$ value. The relative fold gene expression value level $\left[2^{-(\Delta \Delta \mathrm{Cq})}\right]$ was subsequently obtained from the $\Delta \Delta \mathrm{Cq}$ value.

Statistical analysis. Results are presented as means \pm standard deviation (SD). Differences of frequencies between specific categories were tested via the Pearson's chi-squared test.
Differences between the numeric variables of the multiple groups of relative mRNA expressions were tested by ANOVA followed by Tukey's post hoc test. Other differences between the numeric variables of two subgroups of thymomas were tested with Student's t-test. The analytical work was performed using JMP IN 5.1 software (SAS Institute). $\mathrm{P}<0.05$ was considered to indicate a statistically significant difference.

\section{Results}

Clinical features. The clinical data of the studied group of 112 patients with thymomas is summarized in Table I. Thymomas of non-MG patients showed significantly higher proportion of invasive tumors $(n=34 ; 79 \%)$ than those with MG $(n=37 ; 54 \% ; P=0.011)$. Autoimmune disorders other than MG were present in $9(8 \%)$ type B thymoma patients, representing autoimmune thyroiditis in 7 cases, and autoimmune atrophic gastritis and stiff man syndrome each in one case. A synchronous malignant neoplasm at the time of diagnosis was present in 10 patients $(9 \%)$ both with type A and type B thymomas; the spectrum of concomitant malignant neoplasms was broad including melanoma, colorectal and prostatic carcinoma, carcinomas of bladder, thyroid, breast, and kidney. Type A thymomas were not significantly different in size (mean $4.5 \pm 1.5 \mathrm{~cm}$ ) than type B thymomas $(5.0 \pm 2.9 \mathrm{~cm}$; $\mathrm{P}=0.178)$. Thymic tumors of non-MG patients $(5.6 \pm 3.5 \mathrm{~cm})$ were significantly larger than those with $\mathrm{MG}(4.5 \pm 2.1 \mathrm{~cm}$; $\mathrm{P}=0.049$ ) at the time of primary surgery.

The age specific characteristics of the studied group of patients with thymomas are given in Table IV. There were no significant differences in frequency of specific WHO subtypes of thymomas as well as in size of tumors between younger and older patients (data not shown). MG positive patients were significantly younger at the time of diagnosis of thymoma $(n=69 ; 52.5 \pm 14.5$ years $)$ than the non-MG patients $(n=43$; $57.0 \pm 13.4$ years; $\mathrm{P}=0.047)$. We have detected a higher proportion of invasive thymomas, as well as higher recurrence rate and presence of synchronous malignancies in the age group over 60 years compared to younger patients.

Immunoexpression of $\beta$-catenin and E-cadherin. Immunohistochemically, $\beta$-catenin and E-cadherin were both expressed in epithelial cells of all subtypes of thymomas as well 
Table IV. Age specific characteristics of patients with thymoma enrolled in the present study.

\begin{tabular}{lcccccc}
\hline $\begin{array}{l}\text { Age, } \\
\text { years }\end{array}$ & Patients, $n$ & $\begin{array}{c}\text { Invasive, } \\
\mathrm{n}(\%)\end{array}$ & $\begin{array}{c}\text { MG, } \\
\mathrm{n}(\%)\end{array}$ & $\begin{array}{c}\text { Other } \\
\text { AID, n (\%) }\end{array}$ & $\begin{array}{c}\text { Recurrences, } \\
\mathrm{n}(\%)\end{array}$ & $\begin{array}{c}\text { Synchronous } \\
\text { malignancy, } \mathrm{n}(\%)\end{array}$ \\
\hline$<60$ & 65 & $39(60)$ & $45(69)$ & $4(6)$ & $4(6)$ & $3(5)$ \\
$>60$ & 47 & $32(68)$ & $24(51)$ & $5(11)$ & $5(11)$ & $7(15)$ \\
\hline
\end{tabular}

AID, autoimmune disorders; MG, myasthenia gravis.

as in TEC in controls. However, its intracellular localization and intensity varied among the subgroups. Both molecules retained the same pattern of distribution in neoplastic tissues as well as in controls. In type A thymomas, the immunoexpression was observed only in the cytoplasm of neoplastic cells (Fig. 1A and B). In thymomas type B, the intensity of immunolabeling increased, being only cytoplasmic in type $\mathrm{B} 1$ and in non-invasive regions of type B2 (Fig. 1C-F). However, it was membranous throughout the neoplastic tissue in type B3 thymomas, and in the invasive front at the periphery of type B2 thymomas (Fig. 1G-J). In controls, only weak $\beta$-catenin and E-cadherin expression was observed in the cytoplasm of medullary TEC and on membranes of cortical TEC (Fig. 2A and B). No nuclear immunopositivity of $\beta$-catenin was observed in tumor cells. Of note, an intense membranous and nuclear positivity was revealed in TEC of Hassall's corpuscles (Fig. 2C and D).

Relative mRNA expression of molecules involved in the Wnt pathway and E-cadherin

mRNA expression according to the histological subtype. Relative mRNA expression of molecules involved in Wnt pathway ( $\beta$-catenin-gene $C T N N B 1$, cyclin D1-gene $C C N D 1$, c-myc-gene $M Y C$, axin2-gene $A X I N 2$ ) and E-cadherin (gene $C D H 1$ ) according to the WHO histological subtype is summarized in Table $\mathrm{V}$ and Fig. 3A. Expression of all molecules was significantly increased in thymomas when compared to controls, except for the expression of axin2 in thymomas type B; the mRNA expression increased gradually from type B1 to type B3 thymoma. Only in thymomas type A, mRNA expression of axin2 was significantly increased.

mRNA expression according to the Masaoka-Koga stage. Comparison of mRNA expression of the studied molecules in invasive versus non-invasive tumors is given in Table VI; the mRNA expression according to Masaoka-Koga stage of thymomas is summarized in Table $\mathrm{V}$ and Fig. 3B. Expression of mRNA of all studied molecules except for axin2 was increased in invasive thymomas, although the statistical significance was reached only for mRNA expression of cyclin D1, c-myc, and E-cadherin. mRNA expression of axin2 was not significantly different between invasive and non-invasive tumors. However, expression of mRNA of axin 2 differed within the subgroup of non-invasive tumors-it was significantly increased in non-invasive thymomas type A when compared to controls $\left[2^{-(\Delta \Delta \mathrm{Cq})}=3.12 \pm 0.27 ; \mathrm{P}=0.020\right]$, as well as to non-invasive thymomas type $\mathrm{B}\left[2^{-(\Delta \Delta \mathrm{Cq})}=3.58 \pm 1.02 ; \mathrm{P}=0.002\right]$.

Increasing mRNA expression of $\beta$-catenin, cyclin D1, c-myc, axin2, and E-cadherin was observed with increasing stage of disease. An inverse tendency was shown for the mRNA expression of axin2 (see Table V).

Association of the mRNA expression and the clinical factors. No statistically significant differences in mRNA expression of any of the studied molecules were observed when comparing the tumors of MG patients to non-MG patients, as well as when comparing patients with synchronous malignancy to those with thymomas only (data not shown). The mRNA expression of all studied molecules was higher in older patients' group (Table VI).

Follow-up. Median follow-up period was 80 months (range 12-150 months). In 9 patients (8\%) a recurrence of the thymoma of the same histological type was observed (Table I) with the mean time to progression after the primary surgery of 63 months (range 23-120 months).

Recurrences were only observed in type B thymomas. All 5 cases of recurrent B2 thymomas, and 3 of 4 cases of recurrent B3 thymomas were diagnosed as invasive, but one B3 thymoma was evaluated as Masaoka-Koga stage I at the time of primary resection. Immunohistochemically, all recurrent cases of B2 thymomas expressed $\beta$-catenin and E-cadherin on membranes of neoplastic cells at the invasive periphery of the tumor mass. Expression of mRNA of $\beta$-catenin, cyclin D1 and E-cadherin was significantly increased in patients with recurrent tumors in comparison to patients without recurrence (Table VI).

Four patients $(3 \%)$ died due to the generalization of type B thymoma 44 to 92 months after the first diagnosis.

\section{Discussion}

The molecular pathogenesis of thymomas has remained largely undiscovered $(2,3)$. Few previous studies have shown association of thymomas type $\mathrm{B}$ with loss of heterozygosity of $A P C$ gene $(4,13,14)$. The APC molecule plays a key role in regulation of the canonical Wnt signaling pathway by preventing the accumulation of molecule $\beta$-catenin in cytoplasm. APC together with axin2 forms the 'destruction complex' leading to proteasomal degradation of $\beta$-catenin (15-18). Inactivation of APC as well as Wnt signaling activation blocks the degradation of $\beta$-catenin, and thus increases its concentration in cytoplasm allowing translocation of $\beta$-catenin to nucleus. Once in nucleus, $\beta$-catenin forms a transcriptional complex. This complex increases the transcription of cyclin D1 and c-myc, and of other molecules, leading to cell growth. Activation of this pathway has been detected in various tumors $(19,20)$. but data concerning the involvement of Wnt signaling in human thymomas are missing. 

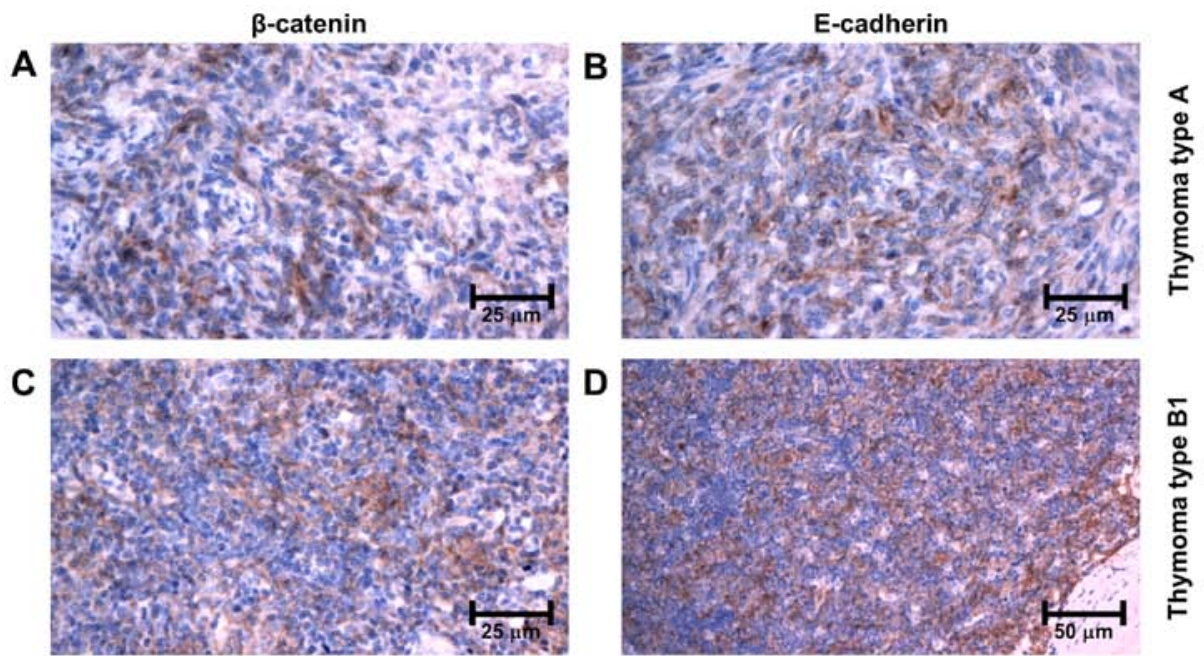

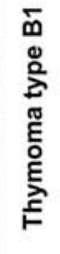
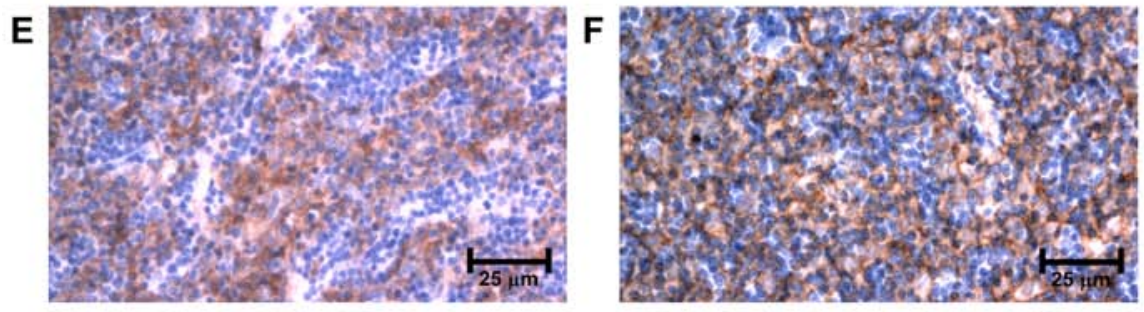

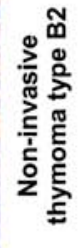
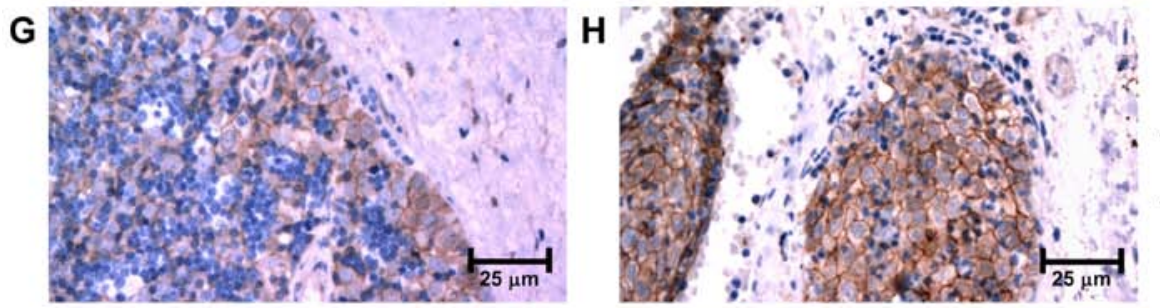

\section{离}
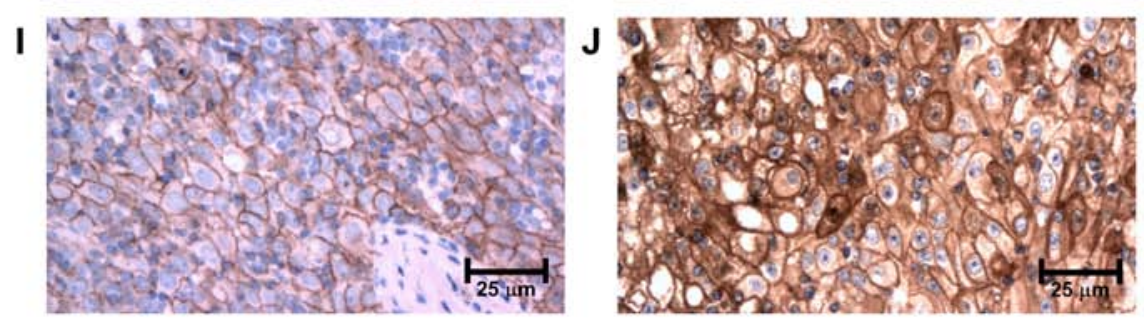

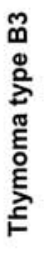

Figure 1. Immunoexpression of $\beta$-catenin and E-cadherin in thymomas type (A and B) A, (C and D) B1 and (E and F) non-invasive type B2 (cytoplasmic expression), in ( $\mathrm{G}$ and $\mathrm{H}$ ) invasive thymomas type $\mathrm{B} 2$ and in (I and $\mathrm{J}$ ) type $\mathrm{B} 3$ (membranous expression).

Liang et al (5) investigated a possible role of the Wnt signaling pathway in initiation and progression of thymomas in mice models by introducing the fusion gene of $\beta$-catenin together with estrogen receptor to the mouse genome. Resulting overexpression of $\beta$-catenin led to increased incidence of thymoma resembling human type $\mathrm{B} 3$ thymomas in those mice.

Our results showed that all the respective molecules are overexpressed also in human thymomas type B, but surprisingly, in thymomas type A as well. Furthermore, we have detected an increasing gradient of mRNA expression of these molecules with increasing thymoma type from B1 up to B3, as well with Masaoka-Koga stage I up to stage IV. This indicates that the levels of mRNA expression correspond with aggressive behavior of thymomas type B. Along with that, the recurrent thymoma cases (all of type B in our study) displayed significantly increased levels of mRNA expression of all molecules when compared to non-recurrent tumors.
Axin2 negatively regulates the Wnt pathway by forming the 'destruction complex' of $\beta$-catenin, which inhibits the Wnt signaling. Axin2 expression in type B thymomas was not significantly different from the control group. However, axin2 was significantly overexpressed in type A thymomas. Non-invasive thymomas type A revealed significantly higher expression of this molecules compared to non-invasive thymomas type B. Thus, the expression of axin 2 corresponds rather to indolent biological nature and lower proliferative capacity of thymomas type A than to Masaoka stage I. Despite the general activation of Wnt pathway in thymomas type A, the negative feedback of axin 2 seems to be preserved.

The molecule of $\beta$-catenin also plays a crucial role in the cell-to-cell adhesion by forming the adherens junction complex together with the cytoplasmic tail of E-cadherin (21). Alteration of this complex in neoplastic cells relates to increased proliferation and ability to metastasize (22). Few previous 
A
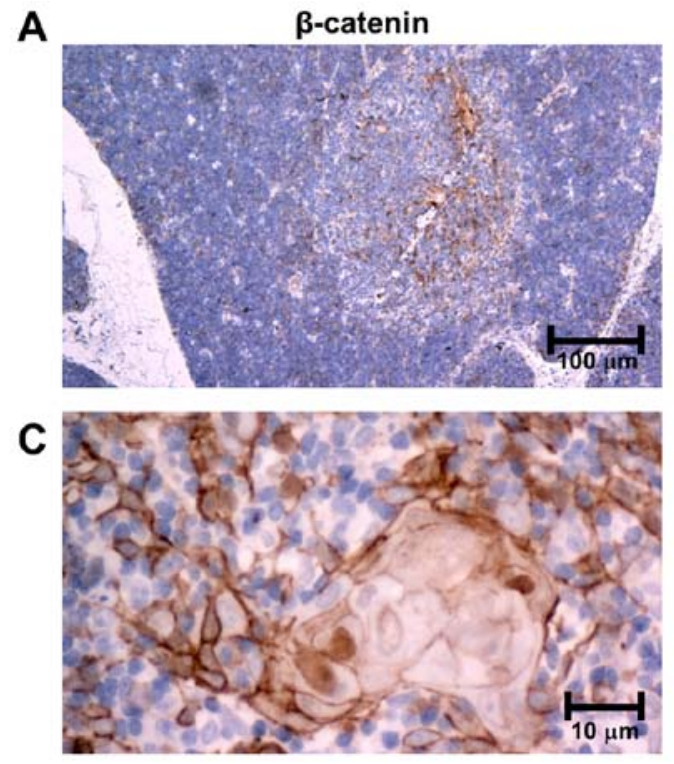

B
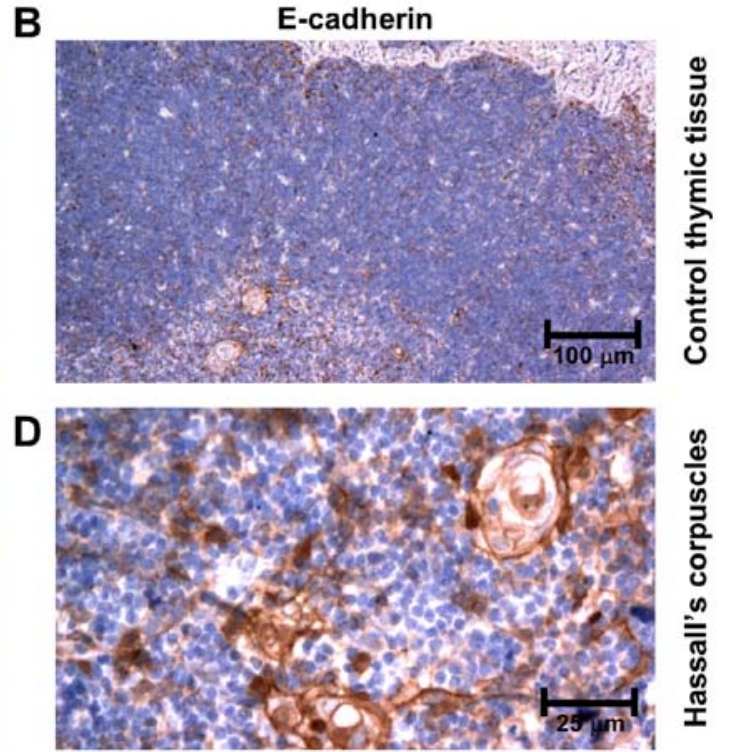

Figure 2. Immunoexpression of $\beta$-catenin, and E-cadherin in (A and B) control thymic tissue, and in (C and D) Hassall's corpuscles of control thymic tissue.
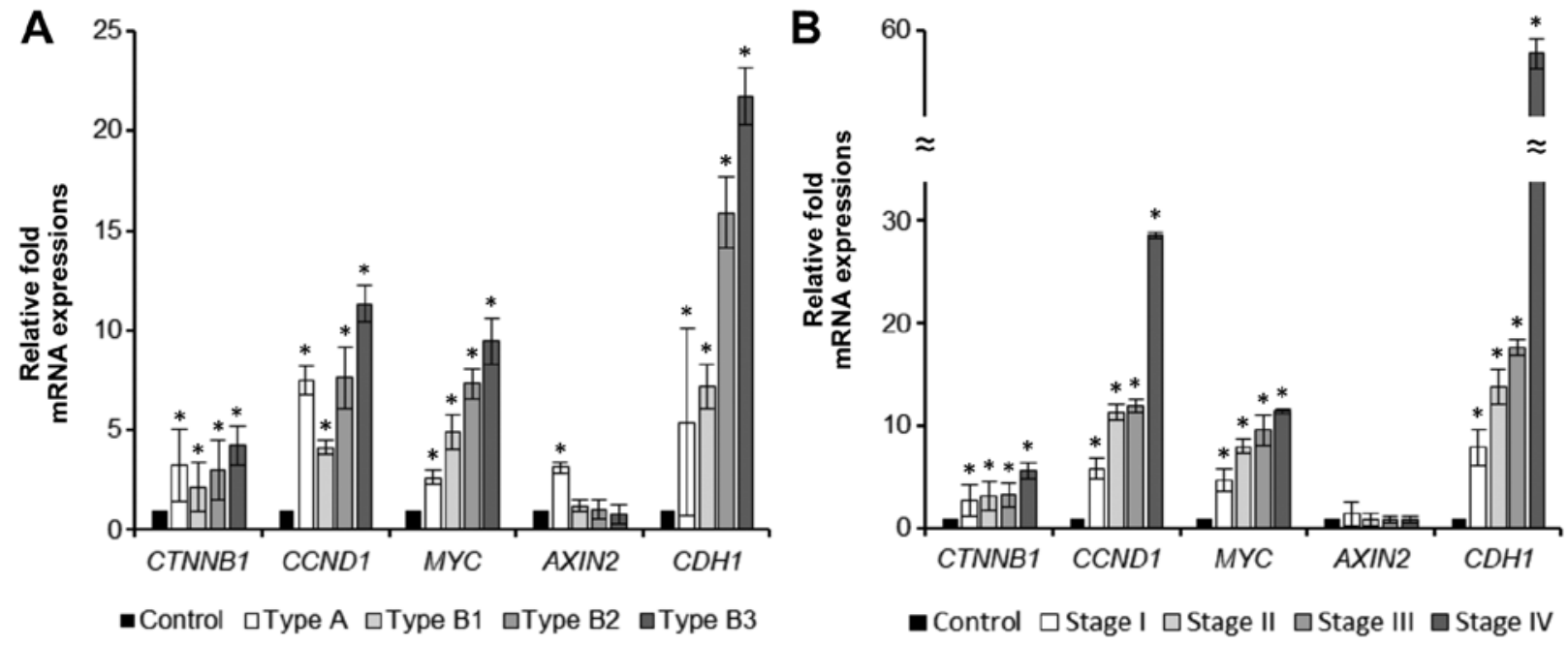

Figure 3. Graphs comparing relative mRNA expression levels of CTNNB1, CCND1, MYC, AXIN2 and CDH1 in thymoma according to (A) histological subtype and (B) Masaoka-Koga stage. Data are presented as the mean \pm SD. ${ }^{*} \mathrm{P}<0.05$ vs. control. CTNNB1, $\beta$-catenin; CCND1, cyclin D1; CDH1, E-cadherin.

studies investigated the immunoexpression of $\beta$-catenin and E-cadherin in thymomas (23-25). Pan et al (26) showed, that the pattern of immunoexpression of $\beta$-catenin differs between thymomas type A (medullary; cytoplasmic) and type B (cortical; membranous). Both $\beta$-catenin and E-cadherin were overexpressed in our thymoma cases, but the localization of expression differed-in thymomas type A, B1 and non-invasive type B2, the positivity of these molecules was localized only in cytoplasm. In contrast, the invasive front of thymomas type B2 and all thymomas type B3 showed intense membranous positivity of both molecules. The membranous positivity was also observed in all recurrent thymomas type B2. Thus, detection of this pattern might be of a good diagnostic utility for detecting potentially aggressive tumors in a group of histologically uniform thymomas type B2.

Nuclear positivity of $\beta$-catenin as a result of activated Wnt pathway has been previously detected in many other tumors (27). However, more recent studies show, that the translocation of $\beta$-catenin to nucleus is more likely a multi-factorial process than just a result of cytosolic accumulation of this molecule, even if the Wnt pathway is activated (28). The nuclear positivity was not detected in any neoplastic cells in our samples. Interestingly, only a minor proportion of cells in Hassall's corpuscles in control thymic tissue showed a nuclear positivity of $\beta$-catenin (Fig. 2C and D).

In our control thymic tissue, low expression of molecules of the Wnt pathway was also observed both on mRNA and protein levels; probably due to the fact that this pathway was shown to be essential for thymocyte development in a normal thymus (29,30). Pongracz et al (31) showed, that Wnt ligands provided by TEC are essential for development of thymocytes. As described by van Loosdregt et al (32) the overexpression of Wnt ligands and thus the activation of Wnt signaling in thymic microenvironment represses function of regulatory $\mathrm{T}$ cells. 
Table V. Relative fold mRNA expression value level $\left(2^{-\Delta \Delta \mathrm{Cq}}\right)$ of molecules involved in the Wnt signaling pathway and E-cadherin based on the expression levels of the target gene vs. the reference housekeeping gene $B 2 M$ in thymoma and control thymic tissue.

\section{A, WHO type}

\begin{tabular}{|c|c|c|c|c|c|c|c|c|c|c|c|}
\hline \multirow[b]{2}{*}{ Type } & \multirow[b]{2}{*}{$\mathrm{n}$} & \multicolumn{2}{|c|}{$C T N N B 1$} & \multicolumn{2}{|c|}{$C C N D 1$} & \multicolumn{2}{|c|}{$M Y C$} & \multicolumn{2}{|c|}{ AXIN2 } & \multicolumn{2}{|c|}{$\mathrm{CDH} 1$} \\
\hline & & Value & P-value & Value & P-value & Value & P-value & Value & P-value & Value & P-value \\
\hline A & 15 & $3.25 \pm 1.81$ & $0.012^{\mathrm{a}}$ & $7.52 \pm 0.73$ & $0.007^{\mathrm{a}}$ & $2.64 \pm 0.32$ & $0.041^{\mathrm{a}}$ & $3.12 \pm 0.27$ & $0.020^{\mathrm{a}}$ & $5.39 \pm 4.70$ & $0.047^{\mathrm{a}}$ \\
\hline B1 & 19 & $2.16 \pm 1.23$ & $0.008^{\mathrm{a}}$ & $4.11 \pm 0.36$ & $0.002^{\mathrm{a}}$ & $4.92 \pm 0.88$ & $0.007^{\mathrm{a}}$ & $1.21 \pm 0.30$ & 0.354 & $7.16 \pm 1.10$ & $0.003^{\mathrm{a}}$ \\
\hline B2 & 41 & $3.01 \pm 1.52$ & $0.001^{\mathrm{a}}$ & $7.62 \pm 1.53$ & $0.008^{\mathrm{a}}$ & $7.31 \pm 0.74$ & $0.005^{\mathrm{a}}$ & $1.03 \pm 0.45$ & 0.488 & $15.89 \pm 1.77$ & $0.001^{\mathrm{a}}$ \\
\hline B3 & 37 & $4.23 \pm 0.98$ & $0.001^{\mathrm{a}}$ & $11.31 \pm 0.90$ & $0.001^{\mathrm{a}}$ & $9.45 \pm 1.15$ & $0.001^{\mathrm{a}}$ & $0.78 \pm 0.50$ & 0.322 & $21.71 \pm 1.39$ & $0.001^{\mathrm{a}}$ \\
\hline
\end{tabular}

B, Stage

\begin{tabular}{|c|c|c|c|c|c|c|c|c|c|c|c|}
\hline \multirow[b]{2}{*}{ Stage } & \multirow[b]{2}{*}{$\mathrm{n}$} & \multicolumn{2}{|c|}{ CTNNB1 } & \multicolumn{2}{|c|}{ CCNDI } & \multicolumn{2}{|c|}{$M Y C$} & \multicolumn{2}{|c|}{ AXIN2 } & \multicolumn{2}{|c|}{$\mathrm{CDH1}$} \\
\hline & & Value & $\mathrm{P}$-value & Value & P-value & Value & $\mathrm{P}$-value & Value & $\mathrm{P}$-value & Value & P-value \\
\hline I & 41 & $2.69 \pm 1.55$ & $0.001^{\mathrm{a}}$ & $5.86 \pm 0.98$ & $0.001^{\mathrm{a}}$ & $4.69 \pm 1.06$ & $0.001^{\mathrm{a}}$ & $1.39 \pm 1.21$ & 0.322 & $7.89 \pm 1.80$ & $0.001^{\mathrm{a}}$ \\
\hline II & 40 & $3.10 \pm 1.39$ & $0.001^{\mathrm{a}}$ & $11.31 \pm 0.78$ & $0.001^{\mathrm{a}}$ & $8.00 \pm 0.69$ & $0.004^{\mathrm{a}}$ & $0.82 \pm 0.61$ & 0.369 & $13.83 \pm 1.67$ & $0.008^{\mathrm{a}}$ \\
\hline III & 17 & $3.25 \pm 1.15$ & $0.001^{\mathrm{a}}$ & $11.96 \pm 0.61$ & $0.001^{\mathrm{a}}$ & $9.58 \pm 1.47$ & $0.003^{\mathrm{a}}$ & $0.85 \pm 0.36$ & 0.381 & $17.63 \pm 0.80$ & $0.002^{\mathrm{a}}$ \\
\hline IV & 14 & $5.66 \pm 0.77$ & $0.001^{\mathrm{a}}$ & $28.64 \pm 0.31$ & $0.003^{\mathrm{a}}$ & $11.47 \pm 0.24$ & $0.004^{\mathrm{a}}$ & $0.82 \pm 0.32$ & 0.354 & $57.68 \pm 1.46$ & $0.001^{\mathrm{a}}$ \\
\hline
\end{tabular}

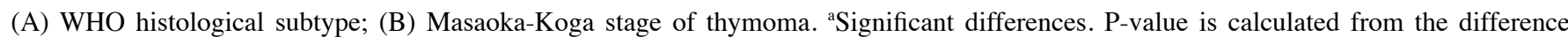
between mRNA expression of each molecule in thymoma vs. control thymic tissue.

Table VI. Relative fold mRNA expression value level $\left(2^{-\Delta \Delta \mathrm{Cq}}\right)$ of molecules involved in the Wnt signaling pathway and E-cadherin based on the expression levels of the target gene vs. the reference housekeeping gene $B 2 M$ between specific subgroups of thymomas.

\begin{tabular}{|c|c|c|c|c|c|c|c|c|c|c|c|}
\hline \multirow[b]{2}{*}{ Subgroups } & \multirow[b]{2}{*}{$\mathrm{n}$} & \multicolumn{2}{|c|}{$C T N N B 1$} & \multicolumn{2}{|c|}{ CCNDI } & \multicolumn{2}{|c|}{$M Y C$} & \multicolumn{2}{|c|}{ AXIN2 } & \multicolumn{2}{|c|}{$\mathrm{CDHI}$} \\
\hline & & Value & P-value & Value & $\mathrm{P}$-value & Value & $\mathrm{P}$-value & Value & P-value & Value & P-value \\
\hline $\begin{array}{l}\text { Invasivity, } \\
\text { Inv./Non-inv. }\end{array}$ & $71 / 41$ & $1.28 \pm 0.30$ & 0.144 & $2.28 \pm 0.94$ & $0.006^{\mathrm{a}}$ & $1.85 \pm 0.53$ & $0.017^{\mathrm{a}}$ & $0.64 \pm 0.43$ & 0.113 & $2.55 \pm 1.69$ & $0.0012^{\mathrm{a}}$ \\
\hline Age, $<60 />60$ & $65 / 47$ & $1.49 \pm 0.31$ & $0.027^{\mathrm{a}}$ & $1.57 \pm 1.10$ & 0.087 & $1.88 \pm 0.70$ & $0.020^{\mathrm{a}}$ & $1.21 \pm 0.21$ & 0.316 & $1.42 \pm 0.99$ & 0.102 \\
\hline $\begin{array}{l}\text { Recurrence, } \\
\text { Rec./No rec. }\end{array}$ & $9 / 103$ & $2.28 \pm 0.85$ & $0.044^{\mathrm{a}}$ & $2.64 \pm 0.67$ & $<0.001^{\mathrm{a}}$ & $0.97 \pm 0.48$ & 0.452 & $2.16 \pm 0.88$ & 0.124 & $3.61 \pm 0.51$ & $0.015^{\mathrm{a}}$ \\
\hline
\end{tabular}

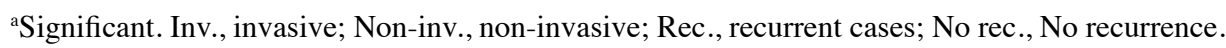

This change is speculated to be the reason for the increased incidence of autoimmune disorders (33), which was also detected in some of our patients with thymomas.

Clinical features of our thymoma cases including the association with autoimmune disorders and the recurrence rate correspond to previously published epidemiological data in thymomas (34-36). Only, we observed slightly increased proportion of $\mathrm{MG}$ patients in the thymoma group. The incidence of $\mathrm{MG}$ in patients with thymoma was higher in younger population and lower in older patients. Along with that, thymomas of younger patients were less invasive and showed lower recurrence rate in our study. Thus, similar to other malignancies of lymphoreticular organs $(6,37)$, the age over 60 years seems to be a negative prognostic factor also in thymomas. The increased size of non-myasthenic thymomas is probably due to delayed manifestation of these tumors with the absence of the $\mathrm{MG}$ and corresponds to higher age at manifestation.

In summary, the activation of Wnt pathway previously detected in animal models is present also in human thymomas and may contribute to the oncogenesis. But, the pattern of expression differs among thymoma subtypes. The detection of some of these molecules of the Wnt pathway might be of a diagnostic and prognostic value. 


\section{Acknowledgements}

Not applicable.

\section{Funding}

The present study was supported by Ministry of Health, Czech Republic-DRO (University Hospital Motol; grant no. 00064203).

\section{Availability of data and materials}

The datasets used and/or analyzed during the present study are available from the corresponding author on reasonable request.

\section{Authors' contributions}

JZ and PV conceived and designed the study. PV and JS collected the tissue samples. JZ reviewed all enrolled tissue samples and supervised the project. PV and JZ performed and interpreted immunohistochemical experiments. LeK and IO performed PCR experiments. LuK, ES and JS collected and evaluated patients' data. PV and JZ were involved in final data analysis and writing the final manuscript. All authors have read, reviewed and approved the final manuscript.

\section{Ethics approval and consent to participate}

The present study was approved by the Ethics Committee at the Second Faculty of Medicine, Charles University, Prague. Written informed consent from each patient/guardian was obtained prior to the enrollment in accordance with the Helsinki protocol.

\section{Patient consent for publication}

Not applicable.

\section{Competing interests}

The authors declare that they have no competing interests.

\section{References}

1. Travis W, Brambilla E, Burke A, Marx A and Nicholson A WHO Classification of Tumours of the Lung, Pleura, Thymus and Heart. IARC Press, Lyon 2015.

2. Li Q, Su YL and Shen WX: A novel prognostic signature of seven genes for the prediction in patients with thymoma. J Cancer Res Clin Oncol 145: 109-116, 2019

3. Girard N: Thymic tumors: Relevant molecular data in the clinic. J Thorac Oncol 5 (10 Suppl 4): S291-S295, 2010.

4. Inoue M, Starostik P, Zettl A, Ströbel P, Schwarz S, Scaravilli F, Henry K, Willcox N,Müller-Hermelink HK and Marx A: Correlating genetic aberrations with World Health Organization-defined histology and stage across the spectrum of thymomas. Cancer Res 63: 3708-3715, 2003.

5. Liang CC, Lu TL, Yu YR, You LR and Chen CM: $\beta$-catenin activation drives thymoma initiation and progression in mice. Oncotarget 6: 13978-13993, 2015.

6. International Non-Hodgkin's Lymphoma Prognostic Factors Project: A predictive model for aggressive non-Hodgkin's lymphoma. N Engl J Med 329: 987-994, 1993.
7. Sehn LH, Berry B, Chhanabhai M, Fitzgerald C, Gill K Hoskins P, Klasa R, Savage KJ, Shenkier T, Sutherland J, et al: The revised International Prognostic Index (R-IPI) is a better predictor of outcome than the standard IPI for patients with diffuse large B-cell lymphoma treated with R-CHOP. Blood 109: 1857-1861, 2007.

8. Girard N, Ruffini E, Marx A, Faivre-Finn C and Peters S; ESMO Guidelines Committee: Thymic epithelial tumours: ESMO Clinical Practice Guidelines for diagnosis, treatment and follow-up. Ann Oncol 5 (Suppl 26): v40-v55, 2015.

9. Boehm T and Swann JB: Thymus involution and regeneration: Two sides of the same coin? Nat Rev Immunol 13: 831-838, 2013.

10. Detterbeck FC, Nicholson AG, Kondo K, Van Schil P and Moran C: The Masaoka-Koga stage classification for thymic malignancies: Clarification and definition of terms. Zhongguo Fei Ai Za Zhi 17: 75-81, 2014 (In Chinese).

11. Bijwaard KE, Aguilera NS, Monczak Y, Trudel M, Taubenberger JK and Lichy JH: Quantitative real-time reverse transcription-PCR assay for cyclin D1 expression: utility in the diagnosis of mantle cell lymphoma. Clin Chem 47: 195-201, 2001.

12. Livak KJ and Schmittgen TD: Analysis of relative gene expression data using real-time quantitative PCR and the 2(-Delta Delta C(T)) method. Methods 25: 402-408, 2001

13. Strobel P, Hohenberger P and Marx A: Thymoma and thymic carcinoma: Molecular pathology and targeted therapy. J Thorac Oncol 5(10 Suppl 4): S286-290, 2010.

14. Zhou R, Zettl A, Ströbel P, Wagner K, Müller-Hermelink HK, Zhang S, Marx A and Starostik P: Thymic epithelial tumors can develop along two different pathogenetic pathways. Am J Pathol 159: 1853-1860, 2001.

15. Hankey W, Frankel WL and Groden J: Functions of the APC tumor suppressor protein dependent and independent of canonical WNT signaling: Implications for therapeutic targeting. Cancer Metastasis Rev 37: 159-172, 2018.

16. Stamos JL and Weis WI: The $\beta$-catenin destruction complex. Cold Spring Harb Perspect Boil 5: a007898, 2013.

17. Yamulla RJ, Kane EG, Moody AE, Politi KA, Lock NE, Foley AV and Roberts DM: Testing models of the APC tumor suppressor/ $\beta$-catenin interaction reshapes our view of the destruction complex in Wnt signaling. Genetics 197: 1285-1302, 2014.

18. Nakamura T, Hamada F, Ishidate $T$, Anai $K$, Kawahara $K$, Toyoshima $\mathrm{K}$ and Akiyama T: Axin, an inhibitor of the Wnt signalling pathway, interacts with beta-catenin, GSK-3beta and APC and reduces the beta-catenin level. Genes Cells 3: 395-403, 1998.

19. Zhang L and Shay JW: Multiple roles of APC and its therapeutic implications in colorectal cancer. J Natl Cancer Inst 109: 2017.

20. Hirschman BA, Pollock BH and Tomlinson GE: The spectrum of APC mutations in children with hepatoblastoma from familial adenomatous polyposis kindreds. J Pediatr 147: 263-266, 2005.

21. Huber AH, Stewart DB, Laurents DV, Nelson WJ and Weis WI: The cadherin cytoplasmic domain is unstructured in the absence of beta-catenin. A possible mechanism for regulating cadherin turnover. J Boil Chem 276: 12301-12309, 2001.

22. Gloushankova NA, Rubtsova SN and Zhitnyak IY: Cadherin-mediated cell-cell interactions in normal and cancer cells. Tissue Barriers 5: e1356900, 2017.

23. Yoshino I, Kase S, Yano T, Sugio K and Sugimachi K: Expression status of E-cadherin and alpha-, beta-, and gamma-catenins in thymoma. Ann Thorac Surg 73: 933-937, 2002.

24. Wang Y, Li L, Li Q, Xie C, Wang E and Wang E: Expression of P120 catenin, Kaiso, and metastasis tumor antigen-2 in thymomas. Tumour Biol 33: 1871-1879, 2012.

25. Riess JW, West R, Dean M, Klimowicz AC, Neal JW, Hoang C and Wakelee HA: GLI1, CTNNB1 and NOTCH1 protein expression in a thymic epithelial malignancy tissue microarray. Anticancer Res 35: 669-676, 2015.

26. Pan CC, Ho DM, Chen WY, Chiang H, Fahn HJ and Wang LS: Expression of E-cadherin and alpha- and beta-catenins in thymoma. J Pathol 184: 207-211, 1998.

27. Kumar R and Bashyam MD: Multiple oncogenic roles of nuclear beta-catenin. J Biosci 42: 695-707, 2017.

28. Morgan RG, Ridsdale J, Tonks A and Darley RL: Factors affecting the nuclear localization of $\beta$-catenin in normal and malignant tissue. J Cell Biochem 115: 1351-1361, 2014.

29. Zuklys S, Gill J, Keller MP, Hauri-Hohl M, Zhanybekova S, Balciunaite G, Na KJ, Jeker LT, Hafen K, Tsukamoto N, et al: Stabilized beta-catenin in thymic epithelial cells blocks thymus development and function. J Immunol 182: 2997-3007, 2009. 
30. Staal FJ, Luis TC and Tiemessen MM: WNT signalling in the immune system: WNT is spreading its wings. Nat Rev Immunol 8: 581-593, 2008

31. Pongracz J, Hare K, Harman B, Anderson G and Jenkinson EJ: Thymic epithelial cells provide WNT signals to developing thymocytes. Eur J Immunol 33: 1949-1956, 2003.

32. van Loosdregt J, Fleskens V, Tiemessen MM, Mokry M, van Boxtel R, Meerding J, Pals CE, Kurek D, Baert MR, Delemarre EM, et al: Canonical Wnt signaling negatively modulates regulatory T cell function. Immunity 39: 298-310, 2013.

33. Evoli A and Lancaster E: Paraneoplastic disorders in thymoma patients. J Thorac Oncol 9 (9 Suppl 2): S143-S147, 2014.

34. Safieddine N, Liu G, Cuningham K, Ming T, Hwang D, Brade A, Bezjak A, Fischer S, Xu W, Azad S, et al: Prognostic factors for cure, recurrence and long-term survival after surgical resection of thymoma. J Thorac Oncol 9: 1018-1022, 2014.

35. Ruffini E, Detterbeck F, Van Raemdonck D, Rocco G, Thomas P, Weder W, Brunelli A, Evangelista A and Venuta F; European Association of Thoracic Surgeons (ESTS) Thymic Working Group: Tumours of the thymus: A cohort study of prognostic factors from the European Society of Thoracic Surgeons database. Eur J Cardiothorac Surg 46: 361-368, 2014.
36. Engels EA and Pfeiffer RM: Malignant thymoma in the United States: Demographic patterns in incidence and associations with subsequent malignancies. Int J Cancer 105: 546-551, 2003.

37. Buske C, Hutchings M, Ladetto M, Goede V, Mey U, Soubeyran P, Spina M, Stauder R, Trnený M, Wedding U, et al: ESMO consensus conference on malignant lymphoma: General perspectives and recommendations for the clinical management of the elderly patient with malignant lymphoma. Ann Oncol 29: 544-562, 2018 .

(7) (3) This work is licensed under a Creative Commons Attribution-NonCommercial-NoDerivatives 4.0 International (CC BY-NC-ND 4.0) License. 